\title{
Equity Theory in the Aged and Their Social Supporter's Relationships
}

\author{
TAKehiro Fujihara \\ Hiroshima University
}

\author{
KAZUMI KIJIMA \\ Notre Dame Seishin University
}

\begin{abstract}
The purpose of this research was to examine the equity theory in the relationships between the aged and their social supporters. The correlations between distress and loneliness in equitable as well as inequitable relationships were investigated by using equity theory. Respondents were sixty eight people aged 65 or older who lived at an old people's home. The results showed that the more benefited the relationship, the higher the Total Mood Index (TMI) scores were. Even if the aged perceived relationships as overbenefited, many of them reported less distress in spite of Walster's theory. The correlation between TMI and loneliness score was significant, and as TMI was high, loneliness score was low.
\end{abstract}

Key words : the aged, social supporter, equity theory, Total Mood Index, loneliness.

It seems that role or transition characterizes individual life span. Illustrations of such role change include getting married, graduation from a school and entrance to a profession, having a child, and so on. There are some characteristics of the transition to the aged. One of them is characteristic role changes that occur with age, such as role loss (e.g. the loss of role of spouse, retirement). This increases dependency, isolation and lowering of morale among aged people. As a consequence, the aged meets with various difficulties involved in role changes.

It is possible to assume that the aged are isolated and feel loneliness as they grow old. However, some studies have reported inconsistent results with such an assumption. Peplau, \& Perlman (1982) pointed that quite a few aged live alone as they grow old, but they do not always feel loneliness. However, little empirical research has been examined this problem.
Also in Japan, some researchers reported that the aged didn't feel as much loneliness as people in general expected. Kudo, Osada, Shimomura (1984) studied the degree of loneliness in the aged with UCLA Loneliness Scale, their coping style and their emotional responses. The results showed that the degree of loneliness was lower in the aged population than in any other age groups.

Though many of the aged didn't feel loneliness and were contented with social relationships, some of them felt loneliness while suffering from psychological pain. In Japan, further increase of the aged population is anticipated in the future. It is, therefore, important for us to find variables and factors which have influence on loneliness of the aged, and then to seek the ways to cope with it.

It is evident by Osada, Hara, Ogihara, \& Inoue (1981) that meaningful communication for the aged can be a successful means of reducing self cognition of isolation and the feeling of loneliness. 
Similarly other researchers (Arling, 1976 ; Perlman, Gerson, \& Spinner, 1978 ; Mullins, Johnson, \& Anderson, 1987) have suggested that loneliness is linked to the friendship.

On the other hand, Kahn \& Antonucci (1980) reviewed, with emphasis on the importance of social support, both for its direct contributions and for its ability to moderate the effect of stress. And the concept of the convey over the life course or personal network was proposed as the structure within which social support was given and was received. Social support is important for older people coming to the transition periods of the life course - retirement and widowhood, for example.

Fujihara, Kijima, Kohyama \& Kurokawa (1987), Fujihara \& Kijima (1988) investigated the degree of loneliness and the structure of social network in the aged. They showed that loneliness was associated with the number of social supporters and that the degree of loneliness was lower when subjects had many supporters.

Previous studies have suggested that both quantity and quality of social supports are linked to loneliness. However, there are few empirical studies which surveyed the dynamic interrelations between the aged and their social supporters. So, in this study, we focused on the interrelation between the aged and their social supporters.

By the way, Walster \& Berscheid (1973) proposed that Equity is a general theory which applies to all human relations. According to the theory, when individuals find themselves participating in inequitable relationship, they become distressed. The more inequitable the relationship is, the more distress individuals feel. The proposition of the theory is as follows :

An equitable relationship exists if person scrutinizing the relationship concludes that all participants are receiving equal relative gains from the relationship ; i.e., where :

$$
\frac{\left(\mathrm{O}_{\mathrm{A}}-\mathrm{I}_{\mathrm{A}}\right)}{\left(\left|\mathrm{I}_{\mathrm{A}}\right|\right)^{\mathrm{K}_{\mathrm{A}}}}=\frac{\left(\mathrm{O}_{\mathrm{B}}-\mathrm{I}_{\mathrm{B}}\right)}{\left(\left|\mathrm{I}_{\mathrm{B}}\right|\right)^{\mathrm{K}_{\mathrm{B}}}}
$$

In the formula (1), $I_{A}$ and $I_{B}$ represent a scrutineer's perception of Person A's and Persons B's inputs. $\left|I_{A}\right|$ and $\left|I_{B}\right|$ are the absolute values of their inputs. The scrutineer's perception of Person A's and Person B's outcomes are designated as $\mathrm{O}_{\mathrm{A}}$ and $\mathrm{O}_{\mathrm{B}}$. Exponents $\mathrm{K}_{\mathrm{A}}$ and $\mathrm{K}_{\mathrm{B}}$ take on the value +1 or -1 , according to the sign of $A$ 's and B's inputs and gains (outputs - inputs).

The purpose of this survey is to examine the equity theory in the relationships between the aged and their social supporters. The correlations between distress and loneliness in equitable as well as inequitable relationships were investigated by using equity theory. Hence, two hypotheses were tested in this study : (a) The aged who perceive themselves as participating in inequitable relationships with their social supporters will report a significantly greater amount of distress than the aged who perceive their relationship as equitable. (b) The higher the distress is, the higher the loneliness scores are.

\section{METHOD}

Respondents : Respondents were sixty eight people above 65 years of age ( 9 males, 59 females) who lived at an old people's homes in Hiroshima and Okayama. Data were collected via individual interviews. The interview included demographic information, social network characteristics (e.g., the number of social supporter, kinds of relations), perceived equity of the relationships with the social supporter, the amount of distress in their relationships, and the 6 items of UCLA Loneliness Scale. A social supporter was defined as "special people who help you facing the stress" .

$81.8 \%$ (54 respondents) of the total respondents had thier social supporters.

The equity measure : The Walster et al. Global Measure of Participants' Inputs, Outcomes, and Equity/Inequity (1978) were used to measure respondents' perceptions of equity in their relation with social supporters. In Japan, Inoue (1985) presented evidence supporting the validity of the equity measure. We asked the respondents the following four questions about the contributions and outcomes of their relationships : 
1. Considering every thing, how would you describe your contributions to your relationship ?

2. Considering every thing, how would you describe your social supporter's contributions to your relationship?

3. Considering every thing, how would you describe your outcomes from your relationship ?

4. Considering every thing, how would you describe your social supporter's outcomes from your relationship?

For each question, responses ranged from extremely low $(-4)$ to extremely high (4) on an 8-point scale.

These estimations enabled us to calculate whether the aged were underbenefited, equitably treated, or overbenefited, by using the formula proposed by Walster et al. Their relationships were classified as follows : greatly underbenefited (GUP), slightly underbenefited (SUB), equitable treated (EQT), slightly overbenefited (SOB), greatly overbenefited (GOB). Equity/Inequity score is calculated with the following formulas (2)(3).

$$
\begin{gathered}
x=\frac{\left(\mathrm{O}_{\mathrm{A}}-\hat{\mathrm{O}}_{\mathrm{A}}\right)}{\left|\mathrm{I}_{\mathrm{A}}\right|} \\
\hat{\mathrm{O}}_{\mathrm{A}}=\mathrm{I}_{\mathrm{A}}+\frac{\left|\mathrm{I}_{\mathrm{A}}\right|^{\mathrm{K}_{\mathrm{A}}\left(\mathrm{O}_{\mathrm{B}}-\mathrm{I}_{\mathrm{B}}\right)}}{\left|\mathrm{I}_{\mathrm{B}}\right|^{\mathrm{K}_{\mathrm{B}}}}
\end{gathered}
$$

Range of Equity/Inequity score of five groups was defined as follows : GUB $(x<-.50)$, SUB $(-.50 \leqq x<.00)$, EQT $(x=.00)$, SOB $(.00<x \leqq .50)$, GOB $(.50<x)$. But practically in this survey, respondents were classified into three groups based on previous studies (Walster et al., 1978; Inoue. 1985) : greatly underbenefited (GUB)-slightly underbenefited (SUB), equitable treated (EQT). slightly overbenefited (SOB), and greatly overbenefited (GOB), because of insufficiency of the number of respondents.

Distress measure ; Austin's Total Mood
Index (reported by Walster et al., 1978) was used to measure the amount of distress in the aged and the social supporters' relationship. The measure consists of four items : contentment, happiness, angriness, and guilt. Respondents were asked, "How content (happy, angry, guilty) do you feel about your overall relationship with your best social supporter ?" Responses for each item were coded not at all (1), a little (2), somewhat (3), and very much (4). Austin's Total Mood Index is calculated by subtracting their angry and guilty scores from the sum of respondents' content and happy scores.

Loneliness measure : Loneliness scale consists of 6 items selected from the UCLA Loneliness Scale, based on prior surveys. The validity and the reliability of the revised UCLA Loneliness Scale were examined by Kudoh \& Nishikawa (1983). Respondents answered on the 4-point scale, i.e., "I never feel this way." (1), "I rarely feel this way." (2), "I sometime feel this way." (3), "I often feel this way." (4). The Loneliness Scale items are as follows : 1) I lack companionship, 2)There is no one I can turn to, 3) I am no longer close to anyone, 4) I feel left out, 5) I am unhappy being so withdrawn, 6) People are around me but not with me. For each respondent, a total loneliness scale score was computed based on the simple sum of the items which applied to the respondents.

\section{RESULTS}

Distress and equity/inequity. According to the previous studies (Walster et al., 1978 ; Inoue, 1985), the aged with inequitable relationships (GUB. SUB), (GOB) would report a significantly greater amount of distress than the aged who perceived their relationships as equitable (EQT.SOB). Results of trend analysis on affective components among (GUB·SUB), (EQT $\cdot \mathrm{SOB}),(\mathrm{GOB})$ are shown in Table 1. Only TMI as a function of equity/inequity relations is put into the form of a figure (Fig. 1). The data were analyzed by one way analysis of variance (equity/inequity relations). The results showed that the main effect 
Table 1 Relationship Between Equity/Inequity of a Supportive Relationship and Mood

\begin{tabular}{crccccc}
\hline Equity/Inequity & $n$ & $\begin{array}{c}\text { Anger } \\
\text { (A) }\end{array}$ & $\begin{array}{c}\text { Guilty } \\
(\mathrm{G})\end{array}$ & $\begin{array}{c}\text { Content } \\
(\mathrm{C})\end{array}$ & $\begin{array}{c}\text { Happy } \\
(\mathrm{H})\end{array}$ & $\begin{array}{c}\text { Total Mood } \\
\text { Index } \\
(\mathrm{C}+\mathrm{H}-\mathrm{A}-\mathrm{G})\end{array}$ \\
\hline GUB-SUB & 10 & 1.90 & 1.90 & 2.60 & 2.60 & 1.40 \\
EQT-SOB & 9 & 2.22 & 2.22 & 2.89 & 3.11 & 1.55 \\
GOB & 35 & 1.49 & 2.69 & 3.23 & 3.31 & 2.37 \\
\hline
\end{tabular}

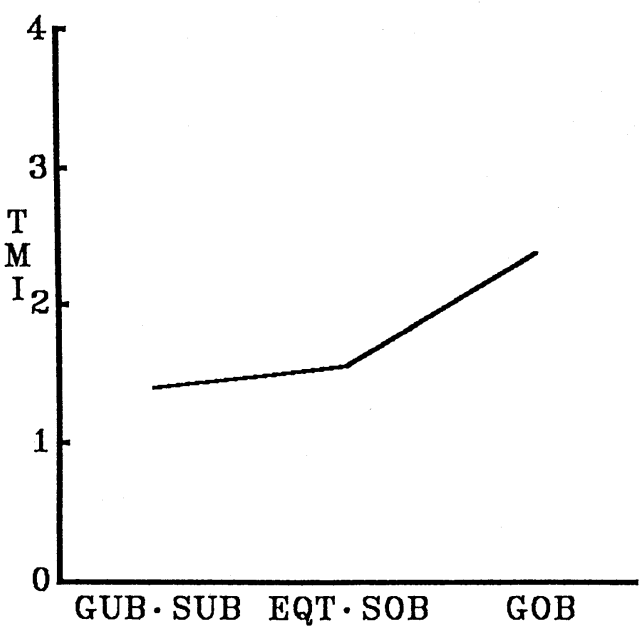

Fig. 1. Equity/Inequity and TMI

of a "anger" was significant $\left[F_{(2)}=4.50, p<.016\right]$. $\mathrm{EQT} \cdot \mathrm{SOB}$ reported significantly greater amount of "anger" than GOB. The main effect of "guilty" was also singificant $\left[F_{(2)}=4.07, p<.023\right]$. The more benefited the relationship is, the more guilty respondents feel. Respondents in GOB reported a significantly greater amount of guilty than respondents in GUB·SUB.

Positive moods (content, happy) were also analyzed. Contrary to the equity theory, the more benefited the relationships, the higher the scores were. The main effect of "happy" was significant $\left[F_{(2)}=3.79, \quad p<.029\right]$. Respondents in GUB.SUB were significantly happier than respondents in GOB. The main effect of "content" was not significant.

The correlation between Total Mood Index (TMI) and equity/inequity score was significant $(r=0.24, p<.08)$. That is, the more benefited the relationships, the higher the TMI scores were (Fig. 1).
Loneliness and affective components. Loneliness scores ranged from 6 to 22 . Mean score on the loneliness scale was $11.58(S D=4.13)$. We examined correlations between loneliness scores and affective components. The results showed that the correlation between TMI and loneliness score was significant $(r=-0.39, p<.004)$. As TMI was high, loneliness score was low, that is to say, the respondents didn't feel loneliness. Especially content in affective components and loneliness were significantly correlated to each other $(r=-0.38, p<.005)$.

\section{DISCUSSION}

The data from this survey suggest that the more beneficial the relationship between the aged and their social supporters is perceived to be, the greater TMI the aged feel, and there are linear trends in happiness and contentment. We find no support for hypothesis 1 : the aged who perceive themselves as participating in inequitable relationship with social supporter will report a significantly greater amount of distress than the aged who perceive their relationship as equitable.

When we think about reasons for the results of this study, we have to consider the fact that the respondents in this study were the aged who lived at an old people's home. Fujihara et al. (1988) showed that most of the aged at an old people's home had few intimate supporters, and they had little contact with intimate supporters. In the above-mentioned study, too, we found a similar result. Living alone was not related to loneliness for the aged, and the aged living alone felt less lonely than those at an old people's home (Fujihara et al. 1987, 1988). Shimonaka (1988) also suggested 
that many of the aged at an old people's home had negative views about personal relationships. It seems that the aged at an old people's home are not satisfied with personal relationship. So they may feel greater happiness and contentment as they perceive personal relationship to be of benefit to them.

Secondly, many of the social supporters of the aged at an old people's home were their relatives (child, sister, brother, etc.). In cases where their supporters are their relatives, respondents have known the social supporters for several decades. In this case, we may have to consider the fact that while respondents had contributed very much to their relationships before, they felt content, happy, angry, and guilty. Therefore, even if the aged perceive relationships as overbenefited, they may report less distress in spite of Walster's theory. In the future, we need to examine relationships between the aged and their social supporters over an extended period of time.

Analyzing the loneliness score, we found a significant correlation between loneliness score and TMI. These findings endorsed the second hypothesis : the higher the distress is, the higher the loneliness score is. Loneliness was associated with the number of social supporters, and the degree of loneliness was lower when subjects had many supporters (Fujihara et al., 1988). And Arling, (1976), Wood, \& Robertson (1987) showed that loneliness was associated with the existence of intimate friends.

However, our study shows that we need to explore the quality of social network, that is, the dynamic interpersonal relationship.

\section{References}

Arling, G. 1976 The elderly widow and her family, neighbors and friends. Journal of Marriage and the Family. 38, 757-767.

Fujihara, T., Kijima, K., Kohyama, T., \& Kurokawa, M. 1987 Survey on the Loneliness and Social Network of the Aegd who Live Alone. Memoirs of the Faculty of Integrated Arts and Sciences III. Hiroshima
University. 11, 43-52.

Fujihara, T., \& Kijima, K. 1988 Survey on the loneliness and social network of the aged who live at an old man's home. Memoirs of the Faculty of Integrated Arts and Sciences III. Hiroshima University. 12, 55-64.

Inoue, K, 1985 An examination of equity theory in dating couples' intimate romantic relationships. The Japaness Journal of Experimental Social Psychology. 24, 127-134.

Kahn, R.L., \& Antonucci, T.C. 1980 Convoys over the Life Course : Attachment, Roles, and Social Support. Life-span Development and Behavior. 3, 253-286.

Kudo, T., \& Nishikawa, M. 1983 A study of the feeling of loneliness (I) : The reliability and validity of the revised UCLA Loneliness Scale. The Japanese Journal of Experimental Social Psychology. 22, 99-108.

Kudo, T., Osada, H., \& Shimomura, Y. 1984 A Factor analytic study of loneliness in the aged. Geriatric social science. 6, 167-185.

Mullins, L.C., Johnson, D.P., \& Anderson, L. 1987 Loneliness of the elderly : The impact of family and friends. Special issue: Loneliness : Theory, research, and applications. Journal of Social Behavior \& Personality, 2, 225-238.

Osada, H., Hara, K., Ogihara, E., \& Inoue, K. 1981 A psychological study of loneliness. Geriatric social science. 3, 111-124.

Peplau, L.A., \& Perlman, D. 1982 Loneliness : A sourcebook of current theory, research and therapy. New York : John Wiley \& Sons.

Perlman, D., Gerson, A.C., \& Spinner, B. 1987 Loneliness among senior citizens: An empirical report, Essence. 2, 239-248.

Shimonaka, Y. 1988 The aged and the personality. Tokyo : Kawashima Shoten Company.

Walster, E., Walster, G.W., and Traupmann, J. 1978 Equity and Premarital Sex. Journal of Personlity and Social Psychology. 36, 82-92.

Walster, E., Berscheid, E., \& Walster, G.W. 1973 New directions in equity research. Journal of Personality and Social Psychology. 25, 151176. 
Takehiro Fujihara and Kazumi Kijima

Wood, V., \& Robertson, J. 1987 Friendship and skinship interaction: Differential effect on the morale of the elderly. Journal of Marriage and the Family. 40, 367-375.

(Received Jun. 30, 1989 ; Accepted Feb. 26, 1990) 